\title{
Historical Mapping
}

\section{Historical Maps}

Maps become out of date over time. Maps that are out of date, however, can be useful to historians, attorneys, environmentalists, genealogists, and others interested in researching the background of a particular area. Local historians can compare a series of maps of the same area compiled over a long period of time to learn how the area developed. A succession of such maps can provide a vivid picture of how a place changed over time.

\section{Researching Historical Maps}

Because different types of historical maps are stored in different collections, they can be difficult to research. However, with a little perseverance, you can find a map that will suit your needs. There are many sources to investigate, ranging from local libraries and historical societies, to State and Federal Government agencies.

The best place to begin research is at a local public or college library. As a first step, you may want to consider locating some of the following books, all of which are good sources of information for the maphunter:

Map Collections in the United States and Canada: A Directory (compiled by David $K$. Carrington and Richard W. Stephenson)

Antique Map Reproductions: A Directory of Publishers \& Distributors of Antique Map, Atlas \& Globe Facsimilies $\&$ Reproductions (edited by Gregory $C$. McIntosh)

Guide to U.S. Map Resources (edited by David A. Cobb)

\section{The National Archives}

The National Archives and Records Administration (NARA), the official repository of the permanently valuable

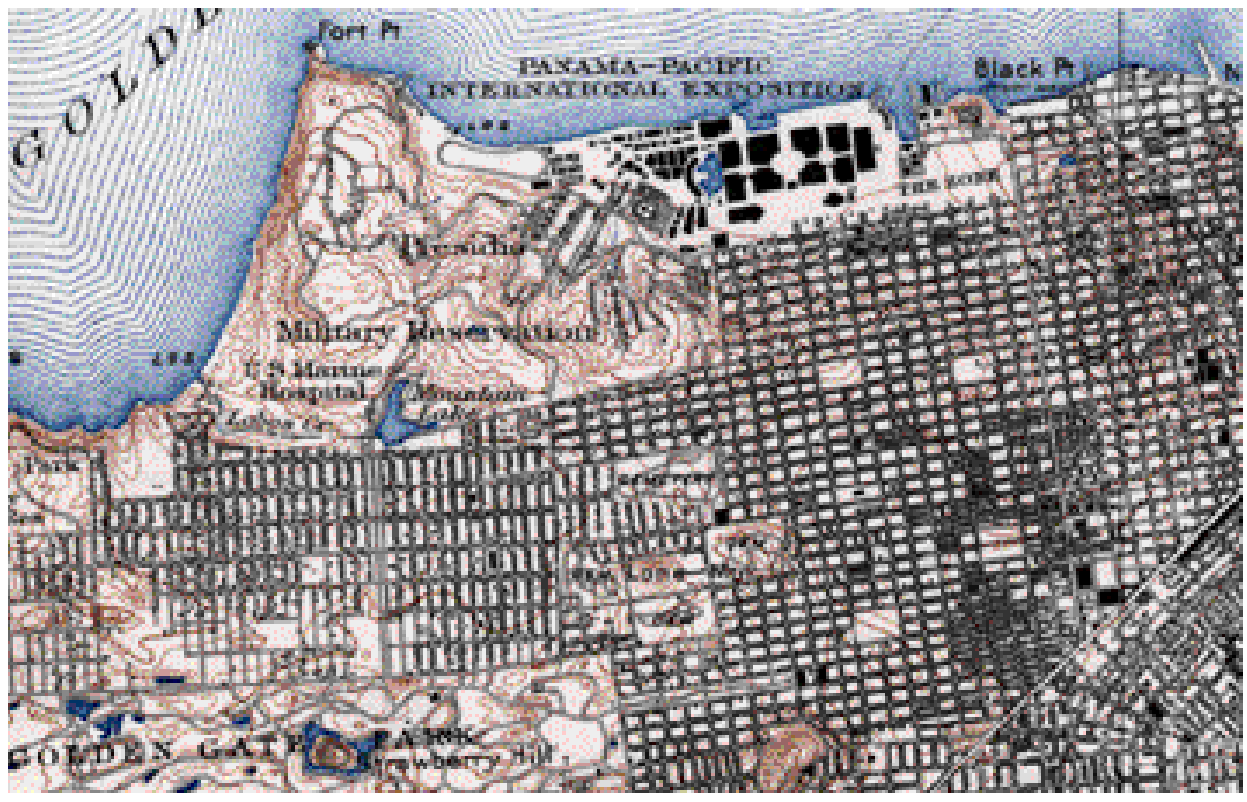

Section from a 1:62,000-scale map of San Francisco, Calif., J une 1915 edition, reprinted in 1929.

records made or accumulated by the U.S. Government, is responsible for preserving those records and making them available to the public, government officials, and scholars. Among the records in the Cartographic and Architectural Branch of the NARA, are more than 2 million maps produced by the Federal Government since 1774.

NARA's holdings relate primarily to official functions of the Federal Government, and records are arranged by the Federal offices that created or accumulated them. Maps that predate the Federal Government and 19th-century maps of areas outside the United States are rare among the Cartographic and Architectural Branch holdings.

The following publications, which can be viewed online, may prove useful in conducting historical map research through NARA:

General Information Leaflet No. 26 Cartographic and Architectural Records http://www.nara.gov/publications/leaflets/ gil26.html
Special List No. 29

List of Selected Maps of States and Territories

http://www.nara.gov/publications/leaflets/ sl29/sl29home.html

To request a search of the maps and charts, researchers need to provide NARA with with a subject, geographic area, and time period. Requests should be addressed to:

Cartographic and Architectural Branch

National Archives

8601 Adelphi Road

College Park, MD 20740-6001

Telephone: 301-713-7040

\section{The Library of Congress}

The Library of Congress serves as the research arm of Congress and is recognized as the national library of the United States. It is the world's largest library and a great resource to scholars and researchers. 


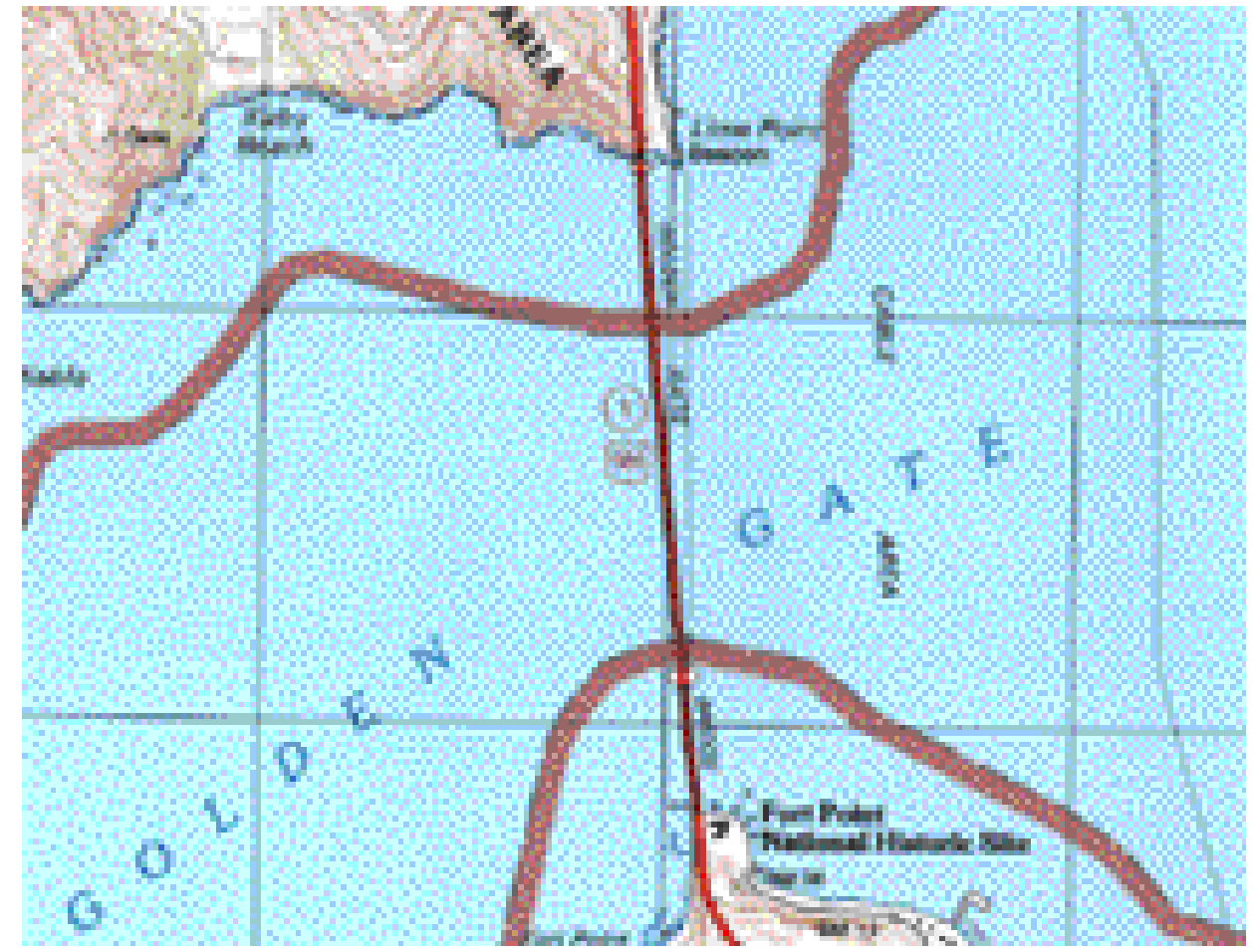

Section from a 7.5-minute topographic map of San Francisco North, Calif., edited in 1996.

In the Geography and Map Division Reading Room of the Library of Congress, researchers can find the largest and most comprehensive cartographic collection in the world, including more than 4.5 million maps and 60,000 atlases, as well as a large number of cartographic materials in other formats.

The following publication, which can be viewed online, is useful for conducting historical map research through the Library of Congress:

Library of Congress Geography and Maps: An Illustrated Guide http://lcweb.loc.gov/rr/geomap/guide

The Geography and Map Division will provide a reasonable amount of basic information about materials in its collection and will serve as the library of last resort for research questions when local resources have been exhausted. Requests should be directed to:

The Geography and Map Division Library of Congress James Madison Memorial Bldg. 101 Independence Ave., S.E.

Washington, DC 20540-4650

E-mail: maps@loc.gov

http://lcweb.loc.gov/rr/geogmap/

\section{Ordering Instructions}

If your are interested in obtaining a reproduction of a particular map from the USGS, you can send a research inquiry to:

\section{ESIC-Reston \\ 507 National Center \\ Reston, VA 20192 \\ Telephone: 703-648-6045 \\ Fax: 703-648-5548}

Your letter of inquiry should give as much information as possible, including the State, county, and town or township; year of interest or range of years; as well as the type of information you are seeking on the map; for example, streams and rivers, railroad lines, roads, or cultural features. A researcher will then be able to determine if any maps in the USGS historical collections will suit your needs.

The reproductions are approximately 24 by 30 inches.

The U.S. Geological Survey (USGS), established in 1879, has a large number of historical topographic maps dating back to 1879 . Recognizing the value of the information contained in older maps, the USGS preserves out-of-print maps on microfilm. In this way, the USGS can limit its vast inventory to the most current maps and still provide copies of older maps.

These out-of-print maps are available for purchase as black-and-white photographic paper reproductions. Although more expensive, the precision of the photographic enlargement procedure results in higher quality prints than electrostatic paper reproductions. However, the sharpness of the reproduction depends on the condition of the original map. Also, because photographic paper is sensitive to light and will eventually fade, such reproductions should not be subjected to bright light for extended periods of time.
Refer to the USGS Maps Price List (stock number 76-0001) for the most recent prices.

\section{Additional Information}

For information on other USGS products and services, call 1-888-ASK-USGS, use the ASK.USGS fax service, which is available 24 hours a day at 703-6484888 , or visit the general interest publications Web site on mapping, geography, and related topics at http://mapping.usgs.gov/www/products/ mappubs.html.

Please visit the USGS home page at http://www.usgs.gov/. 